\title{
Reversibility of insulin resistance in obese diabetic patients: role of plasma lipids
}

\author{
G . M ingrone ${ }^{1}$, A . D eG aetano ${ }^{2}$, A .V. G reco ${ }^{1}$, E . C apristo ${ }^{1}$, G . B enedetti ${ }^{1}$, M . C astagneto ${ }^{2,3}$, G . G asbarrini $^{1}$ \\ ${ }^{1}$ Istituto di Medicina Interna e Geriatria, Università Cattolica S. Cuore, Rome, Italy \\ ${ }^{2}$ CNR, Centro di Studio per la Fisiopatologia dello Shock, Università Cattolica S. Cuore, Rome, Italy \\ ${ }^{3}$ Istituto di Clinica Chirurgica, Università Cattolica S. Cuore, Rome, Italy
}

Summary The aim of the present study was to measure whole body glucose uptake (M) and oxidation rate by euglycaemic hyperinsulinaemic clamp and indirect calorimetry in 7 morbidly obese subjects $\left(\mathrm{BMI}>40 \mathrm{~kg} / \mathrm{m}^{2}\right)$ at three time points: before biliopancreatic diversion (BPD) surgery (Ob); 3 months after surgery $\left(\mathrm{PO}_{\mathrm{I}}\right)$; and after reaching stable body weight, at least 2 years after surgery $\left(\mathrm{PO}_{\mathrm{II}}\right)$. A group of 7 control subjects $(\mathrm{C})$, matched groupwise for sex, age and $\mathrm{BMI}$ with $\mathrm{PO}_{\mathrm{II}}$ patients, was also studied. The $\mathrm{M}$ value at $\mathrm{PO}_{\mathrm{I}}$ was significantly higher than at $\mathrm{Ob}\left(49.12 \pm 8.57\right.$ vs $\left.18.14 \pm 8.57 \mu \mathrm{mol} \cdot \mathrm{kg}^{-1} \cdot \mathrm{min}^{-1}\right)$. No statistical difference was observed between the $\mathrm{PO}_{\mathrm{II}}$ and $\mathrm{C}$ groups. Similarly, glucose oxidation rate was significantly increased at $\mathrm{PO}_{\mathrm{I}}$ with respect to $\mathrm{Ob}$ $\left(24.2 \pm 7.23\right.$ vs $\left.9.42 \pm 3.91 \mu \mathrm{mol} \cdot \mathrm{kg}^{-1} \cdot \mathrm{min}^{-1}\right)$ and was not significantly different between $\mathrm{PO}_{\mathrm{II}}$ and $\mathrm{C}$. Basal levels of non-esterified fatty acids (NEFA) decreased significantly both from $\mathrm{Ob}$ to $\mathrm{PO}_{\mathrm{I}}$ and from $\mathrm{PO}_{\mathrm{I}}$ to $\mathrm{PO}_{\mathrm{II}}(1517.1 \pm 223.9$ vs $1039.6 \pm 283.4$ vs $616.0 \pm$ $\left.77.6 \mu \mathrm{mol} \cdot 1^{-1}\right)$. The same applied to basal plasma triglycerides $(2.07 \pm 0.77$ vs $1.36 \pm 0.49$ vs $0.80 \pm 0.19 \mathrm{~g}$. $\left.\mathrm{l}^{-1}\right)$. Weight decreased mainly in the late postoperative period $\left(\mathrm{PO}_{\mathrm{I}}\right.$ to $\mathrm{PO}_{\mathrm{II}} 124.28 \pm 11.22$ to $69.71 \pm 11.78$, $83 \%$ of total decrement), rather than in the early postoperative period $\left(\mathrm{Ob}\right.$ to $\mathrm{PO}_{\mathrm{I}} 135.25 \pm 14.99$ to $124.28 \pm 11.22 \mathrm{~kg}, 17 \%$ of total decrement). We also report the clinical case of a young woman of normal weight, who underwent BPD for chylomicronaemia (secondary to familial lipoprotein lipase deficiency), whose $M$ value, plasma insulin and blood glucose levels were normalized upon normalization of serum NEFA and triglyceride levels as determined by the therapeutic lipid malabsorption. In conclusion, in obese diabetic patients lipid malabsorption induced by BPD causes a definite enhancement of insulin sensitivity and glucose tolerance. This improvement in metabolism is noticeable before the surgery has major effects on body weight. These observations suggest that lowered plasma lipids, rather than weight loss per se, are the cause of the reversibility of insulin resistance. [Diabetologia (1997) 40: 599-605]

Keywords Insulin resistance, bilio-pancreatic diversion, glucose oxidation, glucose storage.
It has been shown in a large sample of the general population, that obesity itself represents an independent risk factor for increased mortality [1,2].

Received: 31 July 1996 and in revised form: 30 December 1996

Corresponding author: G. Mingrone, MD, PhD, Istituto di Medicina Interna e Geriatria, Università Cattolica S. Cuore, Largo A. Gemelli, 8, I-00168 Rome, Italy

A bbreviations: NIDDM, Non-insulin-dependent diabetes mellitus, BPD, biliary-pancreatic diversion, TBW, total body water, HGO, hepatic glucose output.
Therefore, obesity and its related disorders constitute one of the most relevant health and social problems of the present era because of the high cost and disability which it imposes on the individual and the community [3-5].

Insulin resistance is a prominent biological marker of obesity. In particular, it is a phenomenon represented by high plasma insulin levels, both in the fasting state and postprandially, and is associated with normal levels of blood glucose. In other words an obese individual needs more insulin to reach a euglycaemic state. This condition is more pronounced in obese 
patients with non-insulin-dependent diabetes mellitus (NIDDM) than in obese individuals without NIDDM or impaired glucose tolerance. There is evidence [6] that to a great extent insulin resistance is a consequence of a reduced glucose deposition as glycogen in skeletal muscle, which makes up $40 \%$ of body weight. The initiating factor seems to be related to a reduced glycogen synthase activity, not involving the enzyme itself, but rather the covalent activation of the entire enzyme system [6]. This notion is supported by studies indicating that a hypocaloric diet may have a number of effects: 1) it may reverse the diabetic state [7]; 2) it may completely reverse the decline in number of insulin receptors and in insulin-receptor tyrosine kinase activity in human adipocytes [8]; 3) it may normalize glucose transporter activity in adipocytes from obese diabetic patients [9].

However, although diet is known to improve insulin-mediated glucose disposal in skeletal muscle, normal insulin sensitivity has never been shown to be definitively restored in obese humans. One major problem in these subjects is the difficulty of achieving a stable reduction to normal weight simply by means of a low-calorie diet. The use of bariatric surgery, in particular bilio-pancreatic diversion (BPD), to induce nutrient malabsorption and adequate weight loss has been shown to be successful in achieving a stable near-normal weight in obese subjects [10-12]. The present study stems from previous clinical observations (unpublished data) on obese patients with NIDDM, who after being treated with variable success with oral hypoglycaemic agents or even with high daily doses of insulin, experienced a complete reversal of NIDDM after weight loss induced by bariatric surgery.

We decided, therefore, to measure whole body glucose uptake and oxidation during a euglycaemic hyperinsulinaemic clamp in a group of morbidly obese subjects $\left(\mathrm{BMI}>40 \mathrm{~kg} / \mathrm{m}^{2}\right)$ before BPD, 3 months after BPD (before substantial weight loss occurred, but after postoperative stabilization and the establishment of massive lipid malabsorption, with subsequent lowering of plasma lipids) and after the attainment of near-normal, constant body weight through BPD surgery (no less than 2 years postoperatively). A control group of normal volunteers was tested in the same way.

The hypothesis to be tested was whether the reversibility of insulin resistance, diagnosed by an oral or intravenous glucose tolerance test in post-obese subjects after BPD [13-15], was confirmed by the euglycaemic hyperinsulinaemic clamp. In this case, we wanted to determine to what extent normalization of insulin sensitivity is associated with the short-term decrease in blood lipid concentration as compared to the long-term body weight loss.

In the present paper we also report data on a clinical case [16]: a normal weight 18 year old female with
Table 1. Anthropometric characteristics of the three groups of subjects examined

\begin{tabular}{lllll}
\hline $\mathrm{n}$ & $\begin{array}{l}\text { Obese } \\
(7)\end{array}$ & $\mathrm{PO}_{\mathrm{I}}$ & $\mathrm{PO}_{\mathrm{II}}$ & $\begin{array}{l}\text { Control } \\
\text { group } \\
(7)\end{array}$ \\
\hline $\begin{array}{l}\text { Sex } \\
(\text { male/female) }\end{array}$ & $4 / 3$ & & & $4 / 3$ \\
$\begin{array}{l}\text { Age (years) } \\
\text { Height }(\mathrm{cm})\end{array}$ & $39.6 \pm 12.9$ & $40 \pm 13.0$ & $42.2 \pm 12.8$ & $41.7 \pm 2.25$ \\
$\begin{array}{l}\text { Weight }(\mathrm{kg}) \\
\text { Body mass }\end{array}$ & $135 \pm 15$ & $124 \pm 11$ & $70 \pm 12$ & $68 \pm 9$ \\
$\begin{array}{l}\text { index }\left(\mathrm{kg} / \mathrm{m}^{2}\right) \\
\text { Fat-free mass } \\
(\mathrm{kg})\end{array}$ & $47.4 \pm 4.7$ & $43.6 \pm 4.3$ & $24.1 \pm 3.2$ & $23.3 \pm 1.4$ \\
Fat mass $(\mathrm{kg})$ & $59 \pm 10$ & $50 \pm 7$ & $19 \pm 4$ & $13 \pm 2$ \\
\hline
\end{tabular}

Data are mean \pm SD

a congenital deficit of lipoprotein lipase, who underwent BPD in order to reduce lipid absorption and plasma levels of triglycerides. Preoperatively this girl was diabetic and insulin resistant; after BPD she not only showed a normalization of lipaemia but also the disappearance of diabetes, unaccompanied by weight loss.

\section{Subjects and methods}

Subjects. The study groups consisted of 7 non-obese healthy volunteers $(\mathrm{C})$ and 7 obese, diabetic patients studied three times: before $(\mathrm{Ob}), 3$ months after BPD $\left(\mathrm{PO}_{\mathrm{I}}\right)$ and after reaching a stable, near-normal body weight for at least 1 year, which was attained between 2 and 3 years after BPD $\left(\mathrm{PO}_{\mathrm{II}}\right)$. Control subjects were matched groupwise for sex, age and body mass index with $\mathrm{PO}_{\mathrm{II}}$ subjects. The anthropometric characteristics of the subjects are reported in Table 1.

In PO subjects duodenal aspiration and bacteriology were performed before enrollment into the study, to examine the frequency of small intestine bacterial overgrowth (possibly affecting calculation of substrate oxidation due to bacterial metabolism): values less than $100 \mathrm{organism} / \mathrm{ml}$ were considered suitable $[13,15]$.

Body composition was estimated on the basis of total body water (TBW) [17] measured by isotopic dilution. On the day preceding the clamp evaluation each subject was given $80 \mu \mathrm{Ci}$ of tritiated water $(100 \mathrm{mCi} / \mathrm{ml})$ in $5 \mathrm{ml}$ of physiological saline solution as an intravenous bolus injection. Blood samples were obtained every $30 \mathrm{~min}$ for $180 \mathrm{~min}$ and the plasma radioactivity counted with a beta-scintillation counter (Model 1600TR; Canberra, Conn., USA). Each determination was obtained in duplicate with $0.5 \mathrm{ml}$ of plasma. The resulting values (dpm) were plotted against time ( $\mathrm{min})$, thus obtaining the steady-state concentration $(\mathrm{dpm} / \mathrm{ml})$ of the tracer, and consequently its apparent volume of distribution (TBW in litres). The fat-free mass $(\mathrm{kg})$ was approximated by dividing the TBW by 0.73 [17].

Subjects were clinically euthyroid, had no evidence of renal, cardiac or hepatic dysfunction and were not treated with drugs (other than those for diabetes) which could affect carbohydrate or insulin metabolism; none of the subjects was a smoker. 
Table 2. Basal values of plasma insulin, plasma NEFA, resting energy expenditure (REE), glucose and lipid oxidation rates

\begin{tabular}{|c|c|c|c|c|}
\hline $\mathrm{n}$ & Obese (7) & $\mathrm{PO}_{\mathrm{I}}$ & $\mathrm{PO}_{\mathrm{II}}$ & Control group (7) \\
\hline Basal plasma insulin $\left(\mathrm{pmol} \cdot \mathrm{l}^{-1}\right)$ & $101 \pm 79^{\mathrm{a}}$ & $48 \pm 33$ & $23 \pm 17$ & $26 \pm 6$ \\
\hline Basal plasma NEFA $\left(\mu \mathrm{mol} \cdot 1^{-1}\right)$ & $1517 \pm 224^{a}$ & $1040 \pm 283^{a}$ & $616 \pm 78^{a}$ & $916 \pm 197$ \\
\hline Triglycerides $\left(\mathrm{g} \cdot \mathrm{l}^{-1}\right)$ & $2.07 \pm 0.77^{\mathrm{a}}$ & $1.36 \pm 0.49^{\mathrm{a}}$ & $0.80 \pm 0.19$ & $1.10 \pm 0.30$ \\
\hline $\operatorname{REE}\left(\mathrm{kJ} \cdot \mathrm{kg}^{-1} \cdot \min ^{-1}\right)$ & $0.095 \pm 0.014$ & $0.093 \pm 0.012$ & $0.102 \pm 0.026$ & $0.089 \pm 0.009$ \\
\hline Basal glucose oxidation rate $\left(\mu \mathrm{mol} \cdot \min ^{-1}\right)$ & $354.0 \pm 186.4$ & $529.0 \pm 69.0$ & $598.2 \pm 198.4$ & $725.8 \pm 177.7$ \\
\hline Basal glucose oxidation rate $\left(\mu \mathrm{mol} \cdot \mathrm{kg}^{-1} \cdot \mathrm{min}^{-1}\right)$ & $4.67 \pm 2.41$ & $7.27 \pm 1.38^{\mathrm{a}}$ & $11.74 \pm 3.06$ & $13.34 \pm 3.07^{\mathrm{b}}$ \\
\hline
\end{tabular}

The values are normalized by $\mathrm{kg}$ of fat-free mass

Data are mean \pm SD ${ }^{\text {a }}$ Significance $(p<0.05$ after Bonferroni correction) of the difference of each cell with respect to its right neighbour cell; ${ }^{\mathrm{b}}$ differences with respect to the relative $\mathrm{PO}_{\mathrm{I}}$ cell

Obese diabetic patients were treated with a therapeutic regimen of 3 tablets per day of oral hypoglycaemic agents (glibenclamide $2.5 \mathrm{mg}$ + metformin $400 \mathrm{mg}$ ) plus a bed-time dose (from 20 to 40 IU) of human intermediate action insulin (Protaphane HM; NovoNordisk, Gentofte, Denmark). This treatment was progressively reduced postoperatively, and by 1 month after surgery was completely discontinued in all cases.

All subjects consumed a weight-maintaining diet consisting of at least $250 \mathrm{~g}$ of carbohydrate per day for 1 week before the study.

The study protocol followed the guidelines of the hospital ethics committee and all subjects gave their written informed consent.

Experimental protocol. The subjects were studied in the postabsorptive state after a 12-14 h overnight fast. Blood glucose level of the diabetic patients was kept below $5.55 \mu \mathrm{mol} / 1$ by small bolus doses of short-acting human insulin (Actrapid HM; Novo Nordisk) until the beginning of the study.

All subjects were admitted to the Department of Metabolic Diseases of the Catholic University School of Medicine in Rome at 19.00 hours on the day before the study. At 07.00 hours on the following morning, indirect calorimetry was started: the infusion catheter was inserted into an antecubital vein; the sampling catheter was introduced in the contralateral dorsal hand vein and this hand was kept in a heated box $\left(60^{\circ} \mathrm{C}\right)$ in order to obtain arterialized blood. A basal blood sample was obtained, from which insulin, glucose, triglycerides and non-esterified fatty acids (NEFA) were measured. At 08.00 hours, after a 12-14 h overnight fast, the euglycaemic hyperinsulinaemic glucose clamp was performed according to DeFronzo et al. [18]. A priming dose of short-acting human insulin was given during the initial $10 \mathrm{~min}$ in a logarithmically decreasing manner, in order to raise acutely the plasma insulin to the desired level. Insulinaemia was then maintained with a continuous infusion of insulin at a rate of $40 \mu \mathrm{U} \cdot \mathrm{m}^{2} \cdot \mathrm{min}^{-1}$ for $110 \mathrm{~min}$. During the clamp, the glucose level was monitored every $5 \mathrm{~min}$ and the infusion rate of a $20 \%$ glucose solution was adjusted following the algorithm detailed by DeFronzo et al. [18]. Because serum potassium levels tend to fall during this procedure, $\mathrm{KCl}$ was given at a rate of $15-20 \mathrm{mEq} / \mathrm{h}$ to maintain the serum potassium between 3.5 and $4.5 \mathrm{mEq} / \mathrm{l}$. The glucose uptake rates of the last $40 \mathrm{~min}$ (between 80 and 120 min of the clamp) were averaged to calculate the overall glucose disposal rate ( $\mathrm{M}$ value).

Arterialized blood samples were collected every $20 \mathrm{~min}$ during the clamp study in order to measure insulin and NEFA concentrations.
The subjects emptied their bladders before starting the study, during the clamp urine was collected to measure the urinary nitrogen loss for each subject, which was used for the calorimetry computations.

Respiratory gas exchange was measured by an open-circuit ventilated-hood system (monitor MBM-100; Deltatrac, Datex Instrumentarium Corporation, Helsinki, Finland). Energy expenditure, respiratory quotient, and substrate oxidation rate were calculated from the oxygen consumption, the carbon dioxide production, and the nitrogen urinary excretion according to Ferrannini [19]. Respiratory gas exchange measurements were started 45 min before starting the clamp to measure the resting energy expenditure and continued during the 120 min of the clamp.

Obese subjects underwent the study three times: first, when scheduled for BPD surgery; second, 3 months after the surgical procedure; third, after at least 1 year of stable body weight (which was at least 2 years after surgery for all subjects). The first and last measurements were separated by an interval of $2.3 \pm 0.6$ years.

A nalytical methods. Serum glucose was measured by the glucose oxidase method using a Beckman Glucose Analyzer II (Beckman Instruments, Fullerton, Calif., USA). Plasma insulin was measured by microparticle enzyme immunoassay (Abbott Imx, Pasadena, Calif., USA). Triglycerides and NEFA were assayed by an enzymatic colorimetric method.

\section{Statistical analysis}

All results are expressed as mean \pm SD unless otherwise specified. Bonferroni-corrected Wilcoxon tests were used to evaluate pre- vs early post-surgery and early vs late post-surgery differences in obese subjects. Bonferroni-corrected Mann-Whitney U-tests were used to compare normal control subjects vs early and normal control vs late post-surgery obese subjects. A $p$ value of less than 0.05 was considered statistically significant.

\section{Results}

Table 2 reports baseline values (i.e. before the start of the clamp experiment) of hormonal and metabolic indicators for the subjects. The fasting insulin concentration was up to three- to four-times higher in the 
Table 3. Glucose disposal during euglycaemic/hyperinsulinaemic clamp

\begin{tabular}{|c|c|c|c|c|}
\hline $\mathrm{n}$ & Obese (7) & $\mathrm{PO}_{\mathrm{I}}$ & $\mathrm{PO}_{\mathrm{II}}$ & Control group (7) \\
\hline $\begin{array}{l}\text { Whole body glucose uptake rate }(\mathrm{M}) \\
\left(\mu \mathrm{mol} \cdot \mathrm{kg}^{-1} \cdot \mathrm{min}^{-1}\right)\end{array}$ & $18.1 \pm 8.6^{\mathrm{a}}$ & $35.5 \pm 9.9$ & $49.1 \pm 8.6$ & $42.7 \pm 9.7$ \\
\hline $\mathrm{M} / \mathrm{I}$ ratio $\left(\mu \mathrm{mol} \cdot \mathrm{kg}^{-1} \cdot \mathrm{min}^{-1} \cdot \mathrm{pmol}^{-1}\right)$ & $0.044 \pm 0.031$ & $0.082 \pm 0.021^{\mathrm{a}}$ & $0.126 \pm 0.015$ & $0.100 \pm 0.031$ \\
\hline Glucose oxidation rate $\left(\mu \mathrm{mol} \cdot \mathrm{kg}^{-1} \cdot \min ^{-1}\right)$ & $9.0 \pm 4.1^{\mathrm{a}}$ & $21.9 \pm 6.2$ & $25.3 \pm 7.6$ & $21.5 \pm 4.1$ \\
\hline Glucose storage rate $\left(\mu \mathrm{mol} \cdot \mathrm{kg}^{-1} \cdot \mathrm{min}^{-1}\right)$ & $9.1 \pm 5.8$ & $13.6 \pm 5.5$ & $23.8 \pm 11.6$ & $21.1 \pm 8.9$ \\
\hline
\end{tabular}

The values are normalized by $\mathrm{kg}$ of fat-free mass

Data are mean \pm SD $p<0.05$ after Bonferroni correction for the difference between each cell and its right neighbour cell

obese, diabetic subjects than in control subjects $\left(100.77 \pm 78.98\right.$ vs $\left.26.20 \pm 6.26 \mathrm{pmol} \cdot \mathrm{l}^{-1}, \quad p<0.05\right)$ : the difference was significant in spite of a large interindividual variability found in the obese patients. At 3 months after BPD, insulin levels had returned to values not statistically different from those of the control subjects.

Resting energy expenditure in $\mathrm{PO}_{\mathrm{II}}$ subjects was significantly $(p<0.05)$ higher than in control subjects, but lower $(p<0.05)$ than in obese subjects. However, when energy expenditure was normalized by fat-free mass, the differences were not significant, since both obese and $\mathrm{PO}_{\mathrm{I}}$ patients had a greater fat-free mass than either $\mathrm{C}$ or $\mathrm{PO}_{\mathrm{II}}$. Obese patients oxidized larger amounts of lipids basally, compared to both $\mathrm{C}$ and $\mathrm{PO}_{\mathrm{II}}$. This was also true for $\mathrm{PO}_{\mathrm{I}}$, although the lipid oxidation rate was significantly $(p<0.05)$ decreased compared to the obese state; again, if the lipid oxidation rate was normalized by fat-free mass, these differences between groups disappeared. Conversely, in the obese patients the amount of glucose oxidized per $\mathrm{kg}$ fat-free mass in the fasting state was significantly lower before than after BPD, it was also lower in $\mathrm{PO}_{\mathrm{I}}$ than in $\mathrm{PO}_{\mathrm{II}}$; on the other hand, control subjects oxidized significantly higher amounts of glucose than $\mathrm{PO}_{\text {II }}$ subjects (Table 2).

During the insulin clamp session the steady-state plasma glucose level was maintained close to the initial values with coefficients of variation ranging from 3.2 to $4.8 \%$. The exogenous glucose infusion rate (M), corresponding to the total body glucose disposal rate minus the possible residual hepatic glucose production is reported in Table 3. Hepatic glucose output (HGO) was not estimated in the present study; however, suppression of HGO does not require very high levels of insulin delivery to the liver [20-22] and insulin levels definitely higher than necessary were achieved in the present study. Therefore, the reported $M$ value can be considered as a good estimate of whole-body glucose uptake - it increased significantly in post-obese subjects compared to their pre-BPD values, even in the early postoperative period (3 months after BPD). No pairwise statistical difference was observed between $\mathrm{PO}_{\mathrm{I}}, \mathrm{PO}_{\mathrm{II}}$ and control subjects.

The glucose oxidation rate, evaluated by indirect calorimetry measurements, and the glucose storage
Table 4. Early $\left(\mathrm{PO}_{\mathrm{I}}-\mathrm{Ob}\right)$ and late $\left(\mathrm{PO}_{\mathrm{II}}-\mathrm{PO}_{\mathrm{I}}\right)$ variations (as absolute values and as percent of total variation) of glucose metabolism indices, of weight, and of serum lipids

\begin{tabular}{|c|c|c|c|}
\hline & \multicolumn{3}{|l|}{ Variation } \\
\hline & Early & Late & Total \\
\hline $\begin{array}{l}\text { Whole body glucose } \\
\text { uptake rate }(\mathrm{M}) \\
\left(\mu \mathrm{mol} \cdot \mathrm{kg}^{-1} \cdot \mathrm{min}^{-1}\right)\end{array}$ & $+17.38(56 \%)$ & $+13.6(44 \%)$ & +30.98 \\
\hline $\begin{array}{l}\text { Glucose oxidation rate } \\
\left(\mu \mathrm{mol} \cdot \mathrm{kg}^{-1} \cdot \mathrm{min}^{-1}\right)\end{array}$ & $+12.9(79 \%)$ & $+3.4(21 \%)$ & +16.3 \\
\hline $\begin{array}{l}\text { Glucose storage rate } \\
\left(\mu \mathrm{mol} \cdot \mathrm{kg}^{-1} \cdot \mathrm{min}^{-1}\right)\end{array}$ & $+4.5(31 \%)$ & $+10.2(69 \%)$ & +14.7 \\
\hline Triglycerides $\left(\mathrm{g} \cdot \mathrm{l}^{-1}\right)$ & $-0.71(36 \%)$ & $-1.27(64 \%)$ & -1.98 \\
\hline NEFA (mmol/l) & $-477.5(53 \%)$ & $-423.6(47 \%)$ & -901.1 \\
\hline Weight (kg) & $-10.97(17 \%)$ & $-54.57(83 \%)$ & 65.54 \\
\hline
\end{tabular}

rate, which represents the difference between the rate of whole body glucose uptake minus the rate of glucose oxidation, exhibited the same qualitative behaviour as the $M$ value (Table 4).

Basal triglyceride and NEFA levels were significantly $(p<0.05)$ higher in obese, diabetic patients than in the other groups. Plasma lipids were lower $(p<0.05)$ in $\mathrm{PO}_{\mathrm{II}}$ than in preoperative obese patients, while no statistical differences were found between $\mathrm{PO}_{\mathrm{II}}$ and normal control subjects.

Finally, in the girl with familial deficit of lipoprotein lipase, we measured serum lipids, plasma insulin and the $M$ value, together with glucose and lipid oxidation rates, both before and 3 months after BPD. Basal lipid oxidation was $9.19 \mu \mathrm{mol} \cdot \mathrm{kg}^{-1} \cdot \mathrm{min}^{-1}$ before BPD and $3.40 \mu \mathrm{mol} \cdot \mathrm{kg}^{-1} \cdot \mathrm{min}^{-1} 3$ months after BPD. Conversely, basal glucose oxidation increased from 4.72 to $19.6 \mu \mathrm{mol} \cdot \mathrm{kg}^{-1} \cdot \mathrm{min}^{-1}$. The $\mathrm{M}$ value was increased almost threefold from 14.67 to $38.11 \mu \mathrm{mol} \cdot \mathrm{kg}^{-1} \cdot \mathrm{min}^{-1}$. The $\mathrm{M} / \mathrm{I}$ ratio passed from 0.03 to $0.08 \mu \mathrm{mol} \cdot \mathrm{kg}^{-1} \cdot \mathrm{min}^{-1} \cdot \mathrm{pmol}^{-1}$. Both glucose oxidation and storage rate increased after BPD: the first from 4.5 to $14.2 \mu \mathrm{mol} \cdot \mathrm{kg}^{-1} \cdot \mathrm{min}^{-1}$ and the second from 10.16 to $23.91 \mu \mathrm{mol} \cdot \mathrm{kg}^{-1} \cdot \mathrm{min}^{-1}$. The metabolic behaviour of this patient was therefore similar to that of obese, diabetic patients who have undergone BPD. This subject increased from 55 to $56 \mathrm{~kg}$ body weight between preoperative and 3 months 
postoperative periods, upon resumption of a liberal diet.

\section{Discussion}

The obese patient population considered here, and the methods used to obtain a stable weight loss are extreme. This investigation included only severely obese individuals, for whom morbidity and mortality rates are high and represent a major problem to national health systems because of the high rates of medical treatment failure. Also, long-term weight stability observed in such subjects after BPD is remarkable when compared to the high tendency to regain weight in medically treated obese patients [23]. The cases studied in the present investigation must therefore be considered as a model of stable weight loss deriving mostly from therapeutically induced lipid malabsorption.

There are controversial hypotheses concerning the causes of the so-called insulin resistance syndrome [24] or syndrome X [25]. No genetic defects of the cell insulin receptors having yet been identified, a post-receptor defect is commonly presumed to be responsible for the insulin resistance in NIDDM. Acquired factors, such as obesity (in particular visceral obesity), glucotoxicity [26] and lipotoxicity, may also cause insulin resistance.

Normalization of plasma glucose has already been demonstrated in obese, diabetic patients after weight loss [27]: this effect was, however, attributed only to the weight loss itself. Beck-Nielsen et al. [27] found, in a group of obese diabetic patients of whom $65 \%$ or more were above the ideal body weight (but with an average body weight less than $100 \mathrm{~kg}$ ), that both insulin sensitivity and insulin binding were normalized after 1 year of treatment with a hypocaloric diet. More recently, Long et al. [28] showed that a loss of about $50 \%$ of excess body weight, obtained by gastric bypass surgery in patients with clinically severe obesity (BMI $48 \pm 8 \mathrm{~kg} / \mathrm{m}^{2}$ ), prevents the progression of impaired glucose tolerance to diabetes by more than 30-fold. These authors again suggested that the weight loss itself induced the improvement in insulin sensitivity.

Nevertheless, the inhibitory role of increased lipid levels on glucose disposal, mediated by increased substrate-driven lipid oxidation, has been largely demonstrated in the literature [29, 30-35]. It would therefore seem reasonable to suspect the lower plasma lipid levels accompanying weight loss to be at least a contributing cause of recovered insulin sensitivity.

In the present study, by considering metabolic alterations due to substantial decrease in plasma lipids, but before most of the postoperative weight loss, we show that insulin resistance in obese, diabetic patients represents a reversible condition linked to the lowering of plasma levels of triglycerides and NEFA.

As summarized in Table 4 the most relevant data concern the normalization of glucose metabolism during euglycaemic hyperinsulinaemic clamp in patients who underwent BPD, noticeable in the early postoperative period. About $56 \%$ of the total increase in whole body glucose uptake was already evident by $\mathrm{PO}_{\mathrm{I}}$. Most of the improvement in glucose oxidation rate (79\% of total) was also observed within 3 months of operation. These changes paralleled those for fasting plasma NEFA levels which fell substantially (53\% of total decrease) in the early postoperative period.

However, the glucose storage rate increased more in the later postoperative period ( 3 months to 2 years, $69 \%$ of total), when the main lowering of triglycerides was also observed (64\% of total). Weight loss was much more substantial in the late $(83 \%$ of total loss) rather than in the early ( $17 \%$ of total loss) postoperative period.

The impressive normalization of glucose utilization occurring after BPD seems therefore to be more clearly associated with the changes in plasma NEFA levels rather than to the loss of weight.

The reversibility of insulin resistance was thus reflected in both glucose oxidation rate and the non-oxidative pathway of glucose disposal [14], although the normalization of glucose storage occurred more slowly than that of glucose oxidation. Observing the behaviour of NEFA and triglyceride levels in operated patients it seems that the decrease in NEFA is associated with the improvement of glucose oxidation, while lowering of triglycerides is associated with the increase of glucose storage. This indirectly suggests a reversibility of enzyme glycogen synthase inhibition found in obese subjects [36, 37], and increased pyruvate dehydrogenase complex activity, which is known to be reduced in obese individuals $[38,39]$. It has been hypothesized that in diabetes there is a shift in substrate utilization from carbohydrates to lipids [40]: a large proportion of the increase in lipid oxidation, characteristic of obesity and obese NIDDM, is accounted for by an increase in intramuscular triglyceride mobilization. An impaired pyruvate dehydrogenase activity [41] and an increase in beta-oxidation enzyme activity [29] have been described in such patients.

The disappearance of diabetes within 3 months of BPD in a normal weight young female, who underwent BPD for chylomicronaemia secondary to a familial deficiency of lipoprotein lipase, and who did not lose weight after the operation (she did, in fact, increase her weight after the operation, due to an unrestricted diet rich in sugary and fatty foodstuffs), confirms that the lipid malabsorption and the lower plasma levels of lipids, rather than the weight loss, 
cause the reversibility of the insulin resistance condition.

Therefore, although the relatively small number of subjects studied did not allow a proper multivariate analysis of the influence of the different variables on the improvement of glucose metabolism, the results in Table 4 suggest that this is primarily dependent on the decrease of plasma lipid level, since it was observed in a subject not decreasing in weight.

In conclusion, in obese, diabetic patients BPD definitely improves glucose utilization, which can be demonstrated by the euglycaemic hyperinsulinaemic clamp technique, and which persists over time reflecting enhanced insulin sensitivity. The evidence indicates that lipid malabsorption has a primary role, with subsequent lowering of plasma NEFA and triglycerides, rather than the simple loss of weight, in the improvement in metabolism.

\section{References}

1. Van Itallie TB (1979) Obesity: adverse effects on health and longevity. Am J Clin Nutr 32 [Suppl]: 2723-2733

2. Manson JE, Willett WC, Stampfer MJ et al. (1995) Body weight and mortality among women. $\mathrm{N}$ Engl J Med 333: 677-685

3. National Institutes of Health Consensus Development Panel on the Health Implications of Obesity (1985) Health implications of obesity. Ann Intern Med 103: 1073-1077

4. Kuczmarski RJ, Flegal KM, Campbell SM, Johnson CL (1994) Increasing prevalence of overweight among US adults. The National Health and Nutrition Examination Surveys, 1960 to 1991. JAMA 272: 205-211

5. Harlan WR, Landis JR, Flegal KM, Davis CS, Miller ME (1988) Secular trends in body mass in the United States, 1960-1980. Am J Epidemiol 128: 1065-1074

6. Beck-Nielsen H, Vaag A, Damsbo P et al. (1992) Insulin resistance in skeletal muscles in patients with NIDDM. Diabetes Care 15: 418-429

7. Beck-Nielsen H, Pedersen O, Sorensen NS (1980) Effects of dietary changes on cellular insulin binding and in vivo insulin sensitivity. Metabolism 29: 482-487

8. Freidenberg GR, Reichart D, Olefsky JM, Henry RR (1988) Reversibility of defective adipocyte insulin receptor kinase activity in non-insulin-dependent diabetes mellitus. Effect of weight loss. J Clin Invest 82: 1398-1406

9. Damsbo P, Handberg A, Beck-Nielsen H (1990) Reversibility of the defect in glycogen synthase activity in skeletal muscle from obese type 2 (non-insulin-dependent) diabetics treated with diet and metformin. Diabetologia 33 [Suppl]: A126 (Abstract)

10. Scopinaro N, Gianetta E, Civalleri D, Bonalumi U, Bachi V (1979) Biliopancreatic bypass for obesity: I. An experimental study in dogs. Br J Surg 66: 613-617

11. Scopinaro N, Gianetta E, Civalleri D, Bonalumi U, Bachi V (1979) Biliopancreatic bypass for obesity: II. Initial experience in man. Br J Surg 66: 618-620

12. Scopinaro N, Gianetta E, Adami GF et al. (1995) Biliopancreatic diversion for obesity at eighteen years. Surgery 119: 261-268

13. Tataranni PA, Mingrone G, Greco AV et al. (1994) Glucose induced thermogenesis in postobese women who have undergone biliopancreatic diversion. Am J Clin Nutr 60: 320-326

14. Castagneto M, De Gaetano A, Mingrone G et al. (1994) Normalization of insulin sensitivity in the obese patient after stable weight reduction with bilio-pancreatic diversion. Obesity Surg 4: 161-168

15. Tataranni PA, Mingrone G, Raguso C et al. (1996) Twentyfour-hour energy and nutrient balance in weight stable postobese patients after biliopancreatic diversion. Nutrition 12: 239-244

16. Gasbarrini G, Mingrone G, Greco AV, Castagneto M (1996) An 18-year-old woman with familial chylomicronemia who would not stick to a diet. Lancet 348: 794

17. Bonora E, Del Prato S, Bonadonna RC et al. (1992) Total body fat content and fat topography are associated differently with in vivo glucose metabolism in nonobese and obese nondiabetic women. Diabetes 41: 1151-1159

18. DeFronzo RA, Tobin JD, Andres R (1979) Glucose clamp technique: a method for quantifying insulin secretion and resistance. Am J Physiol 273: E214-E223

19. Ferrannini E (1988) The theoretical bases of indirect calorimetry: a review. Metabolism 3: 287-301

20. Ferrannini E, Barrett E, Bevilacqua S (1983) Effect of fatty acids on glucose production and utilization in man. $\mathrm{J}$ Clin Invest 72: 1737-1747

21. Del Prato S, Enzi G, Vigili de Kreutzenberg S et al. (1990) Insulin regulation of glucose and lipid metabolism in massive obesity. Diabetologia 33: 228-236

22. Petrides AS, Groop LC, Riely CA, DeFronzo RA (1991) Effect of physiologic hyperinsulinaemia in glucose and lipid metabolism in cirrhosis. J Clin Invest 88: 561-570

23. Brownell KD, Rodin J (1994) Medical, metabolic, and psychological effects of weight cycling. Arch Intern Med 154: $1325-1330$

24. DeFronzo RA, Ferrannini E (1991) Insulin resistance: a multifaceted syndrome responsible for NIDDM, obesity, hypertension, dyslipidemia, and atherosclerotic cardiovascular disease. Diabetes Care 14: 173-194

25. Reaven GM (1988) Role of insulin resistance in human disease. Diabetes 37: 1595-1607

26. Marshall S, Garvey WT, Traxinger RR (1991) New insights into the metabolic regulation of insulin action and insulin resistance: role of glucose and amino acids. FASEB J 5: 3031-3035

27. Beck-Nielsen H, Pedersen O, Lindskov HO (1979) Normalization of the insulin sensitivity and the cellular insulin binding during treatment of obese diabetics for one year. Acta Endocrinol 90: 103-112

28. Long ST, O'Brien K, MacDonald KG et al. (1994) Weight loss in severely obese subjects prevents the progression of impaired glucose tolerance to type II diabetes. Diabetes Care 17: 372-375

29. Randle PJ, Garland PB, Hales CN, Newsholme EA (1964) The glucose fatty acid cycle and diabetes mellitus. Aetiology of diabetes mellitus and its complications. In: Ciba Foundation, Cameron MG, O'Connor M (eds) Colloquia on Endocrinology 15. J \& A Churchill Ltd, London, pp 192-216

30. Bonadonna RC, Zych K, Boni C, Ferrannini E, DeFronzo RA (1989) Time dependence of the interaction between lipid and glucose in man. Am J Physiol 257: E49-E56

31. Boden G, Jadali F, White J et al. (1991) Effects of fat on insulin-stimulated carbohydrate metabolism in normal men. J Clin Invest 88: 960-966

32. Lee Y, Hirose H, Ohneda M, Johnson JH, McGarry JD, Unger RH (1994) $\beta$-cell lipotoxicity in the pathogenesis of non-insulin-dependent diabetes mellitus of obese rats: 
impairment in adipocyte- $\beta$-cell relationship. Proc Natl Acad Sci 91: 10878-10882

33. Paolisso G, Tataranni PA, Foley JE, Bogardus C, Howard BV, Ravussin E (1995) A high concentration of fasting plasma non-esterified fatty acids is a risk factor for the development of NIDDM. Diabetologia 38: 1213-1217

34. Feskens EJM, Virtanen SM, Rasanen L et al. (1995) Dietary factors determining diabetes and impaired glucose tolerance. A 20-year follow-up of the Finnish and Dutch cohorts of the Seven Countries Study. Diabetes Care 18: 1104-1112

35. Laville M, Rigalleau V, Riou JP, Beylot M (1995) Respective role of plasma nonesterified fatty acid oxidation and total lipid oxidation in lipid-induced insulin resistance. Metabolism 44: 639-644

36. Damsbo P, Vaag A, Hother-Nielsen O, Beck-Nielsen H (1991) Reduced glycogen synthase activity in skeletal muscle from obese patients with and without type 2 (non-insulin-dependent) diabetes mellitus. Diabetologia 34: 239245
37. Freymond D, Bogardus C, Okubo M, Stone K, Mott D (1988) Impaired insulin-stimulated muscle glycogen synthase activation in vivo in man is related to low fasting glycogen synthase phosphatase activity. J Clin Invest 82: 1503-1509

38. Beck-Nielsen H, Wright K, Verity L, Bell JM, Kolterman P, Mandarino LJ (1987) Reduced glucose oxidation and pyruvate-dehydrogenase activity $(\mathrm{PDH})$ in type I diabetics (insulin-dependent) in poor control. Diabetes 36 [Suppl 1] 30A (Abstract)

39. Kelley DE, Mandarino LJ (1990) Hyperglycemia normalizes insulin-stimulated skeletal muscle glucose oxidation and storage in noninsulin-dependent diabetes mellitus. J Clin Invest 86: 1999-2007

40. Kiens B, Essen-Gustavsson B, Gad P, Lithell H (1987) Lipoprotein lipase activity and intramuscular triglyceride stores after long-term high-fat and high carbohydrate diets in physically trained men. Clin Physiol 7: 1-9

41. Beck-Nielsen H (1989) Insulin resistance in skeletal muscles of patients with diabetes mellitus. Diabetes Metab Rev 5: 487-493 